\title{
Development of a code in python programming language to generate Ashby chart applied for materials selection.
}

Víctor Hidalgo1,2, * José Erazo2, Mario Granja1, Carlos Díaz3, Ignacio Benavides4, 1 Dpto. de Ingeniería Mecánica, Escuela Politécnica Nacional, Ladrón de Guevara E11253, 170517 Quito, Ecuador

2 Laboratorio de Mecánica-Informática, Escuela Politécnica Nacional, Ladrón de Guevara E11-253, 170517 Quito, Ecuador

3 Dpto. de Materiales, Escuela Politécnica Nacional, Ladrón de Guevara E11-253, 170517 Quito, Ecuador

4 Facultad de Ciencias Aplicadas, Universidad Técnica del Norte, Av. 17 de Julio 5-21, Ibarra, Ecuador

*victor.hidalgo@epn.edu.ec

\section{ABSTRACT}

Abstract. This study focuses on the development of a programming code to generate Ashby charts, which are used to optimize the mechanical design process in terms of reduction the materials selection time. The platform developed was carried out using python programming language and a database composed of 75 different types of materials that have been categorized in 7 regions (metals, ceramics, polymers, elastomer, natural, foams and composites) with their respective mechanical and thermal properties (Young's modulus, density, mechanical strength, thermal conductivity, thermal expansion and maximum service temperature). In order to perform the charts Ashby, the code first generates bubble diagrams in logarithm scale using the range of values of two desired properties, and then, these diagrams are grouped into regions through an envelope that is created using analytic geometry. For validation of the platform and the methodology, the obtained Ashby charts results were contrasted with charts provided by the CES Edupack 2017 software, from there the percentage of differences between the model developed and baseline charts were among of 2,8\% to $15 \%$. In consequence, the Ashby Charts obtained with the proposed code they are suitable for use in the selection of material.

Key words: Ashby charts, materials selection, programming code, Python. 


\section{Introduction}

Materials selection is an important stage in the mechanical design since it ensures the appropriate operation, minimizes costs and defines the manufacturing process for the designed parts [1]. However, this stage is iterative and presents problems in some cases, due to there are around 160000 available materials and choosing the right one depends most of the time, only from the designer's experience or preference $[1,2]$. For this reason, practical methods have been developed in the last years, in order to provide designers with a tool that is capable to reduce and optimize the time spent performing the selection task [3]. In this context, the graphical selection method proposed by Michael F. Ashby has gained a special interest in the preliminary design stage, since it allows defining quickly the appropriate material using a scatter diagrams that are known as Ashby charts [4].

In the aforementioned diagrams the materials are categorized into seven regions or families (metals, ceramics, polymers, elastomer, naturals, foams and composites) and the values range of their mechanical, electrical and thermal properties such as density or mechanical strength, are represented through bubble diagrams [5]. Moreover, these diagrams are characteristic of each pair of properties and are sketched on logarithmic scale in order to allow that the material index can be represented by a straight line [6]. Regarding the last point, each diagram includes a series of material indices, which allow to characterize the performance of a material in a given application of design [7].

Nowadays, there is a variety of software that can be use in the design industry for application of the graphical selection method such as CES Edupack, MATLAB, Excel, among others. However, these programs are licensed and present a black box structure, which limits its use for research [8]. For this reason, the present study focuses on developing an open source code for creating Ashby Charts. In this context, the code is written in Python programming language and it will allow selecting materials according the needs of design. 


\section{Methodology}

The programming code for generating Ashby Charts presented in this work is the result of the application of a systematic methodology, which has been divided into 3 stages for a better understanding. These stages are database collection, development of code base and development of the graphical user interface (GUI).

\section{Data Collection}

Database used for the programming code is composed for 75 different types of materials that can be applied in the mechanical design. The information needed to create it was extracted from several bibliographic sources such as: "Materials Selection in Mechanical Design" of M. F. Ashby, "Fundamentals of Material Science and Engineering" of W.D.Callister and "Materials selection desk book" of N. P. Cheremisinoff $[2,9,10]$.

As shown in the Table 1, the obtained information has been organized into 18 fields. The first five fields contain the general data about each of the 75 materials, while the next fields contain the minimum and maximum values of their mechanical and thermal properties. In addition, a final field is included with the purpose of add notes on materials that may be relevant to the researcher.

Table 1. Structure of database

\begin{tabular}{|l|l|l|l|}
\hline Field 1 & Material Number & Field 10 & $\begin{array}{l}\text { Minimum value of Mechanical } \\
\text { resistance in [Mpa] }\end{array}$ \\
\hline Field 2 & Region & Field 11 & $\begin{array}{l}\text { Maximum value of Mechanical } \\
\text { resistance in [Mpa] }\end{array}$ \\
\hline Field 3 & Family & Field 12 & $\begin{array}{l}\text { Minimum value of Thermal } \\
\text { conductivity in [W/mK] }\end{array}$ \\
\hline Field 4 & Subfamily & Field 13 & $\begin{array}{l}\text { Maximum value of Thermal } \\
\text { conductivity in [W/mK] }\end{array}$ \\
\hline Field 5 & Material name & Field 14 & $\begin{array}{l}\text { Minimum value of Thermal } \\
\text { expansion coef.[10-6/oC] }\end{array}$ \\
\hline Field 6 & $\begin{array}{l}\text { Minimum value of density } \\
\text { [Kg/m3] }\end{array}$ & Field 15 & $\begin{array}{l}\text { Maximum value of Thermal } \\
\left.\text { expansion coef.[10-6/ }{ }^{\circ} \mathrm{C}\right]\end{array}$ \\
\hline Field 7 & $\begin{array}{l}\text { Maximum value of density } \\
\text { Kg/m3] }\end{array}$ & Field 16 & $\begin{array}{l}\text { Minimum value of Max. Operating } \\
\left.\text { temperature. [ }{ }^{\circ} \mathrm{C}\right]\end{array}$ \\
\hline Field 8 & $\begin{array}{l}\text { Minimum value of Young's } \\
\text { Modulus in [Gpa] }\end{array}$ & Field 17 & $\begin{array}{l}\text { Maximum value of Max. operating } \\
\left.\text { temperature [ }{ }^{\circ} \mathrm{C}\right]\end{array}$ \\
\hline Field 9 & $\begin{array}{l}\text { Maximum value of Young's } \\
\text { Modulus in [Gpa] }\end{array}$ & Field 18 & \begin{tabular}{l} 
Note \\
\hline
\end{tabular} \\
\hline
\end{tabular}




\section{Development of the codebase}

The development of the codebase was carried out under the free software guidelines using Python programming language. As shown in the Fig. 1., this code performs 6 general process in order to display the Ashby Charts.

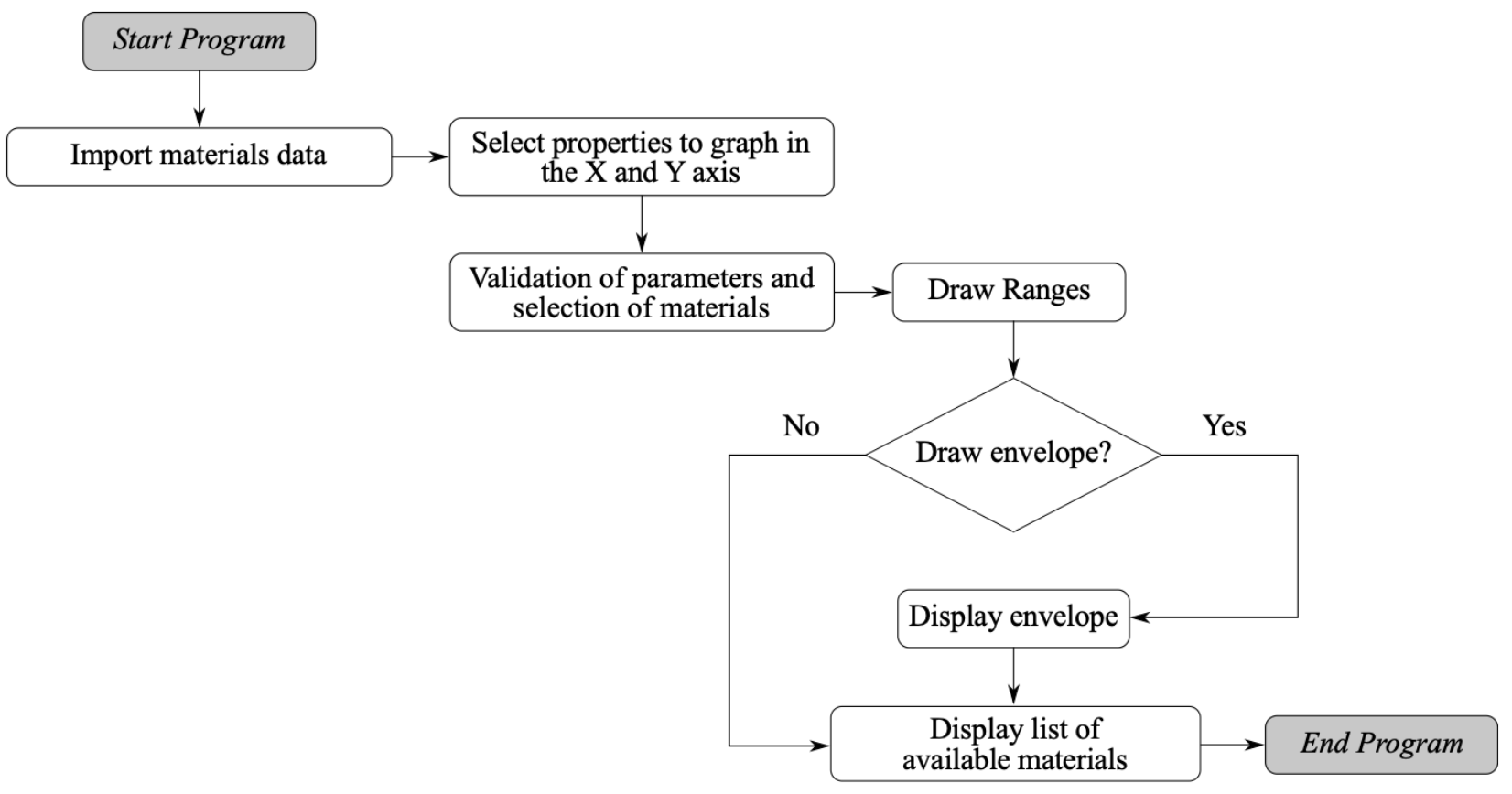

Fig. 1. Structure of the codebase

Import material data. - This process was done through the $<<$ Data import $>>$ function that was implemented in codebase. For the data import, the "xIrd" library was applied. This library reads and extracts all data from file $<$ Material database. $\mathrm{xml}>$ into a variable of type list.

Materials Selection. - This procedure was performed by using the $<<$ Validation parameters $>>$ function. This function first extracts all user parameters that are defined according to design needs, and then based on these parameters a new list called <Regions list $>$ is created. Finally, this list is divided into 7 lists that corresponds to each of the materials families.

Diagrams creation. - This process aims to sketch Ashby diagrams on logarithmic scale and was performed through the $\langle<$ Graph $>>$ function. It consists of two sub-process: the first process plots the bubbles or ellipses that represent the ranges of the properties of each material; and the second process plots the envelope that groups the bubbles belonging to various materials.

i) Bubbles diagrams. - In order to perform this process, it was necessary to implement an own function that was capable of graphing ellipses on logarithmic scales. As shown in the Figure 2. the implemented $<<$ Materials range $>>$ function first constructs a rectangle whose sides correspond to the maximum and minimum ranges of each property and then, on this rectangle the ellipse is inscribed taking as reference 4 tangent points. 


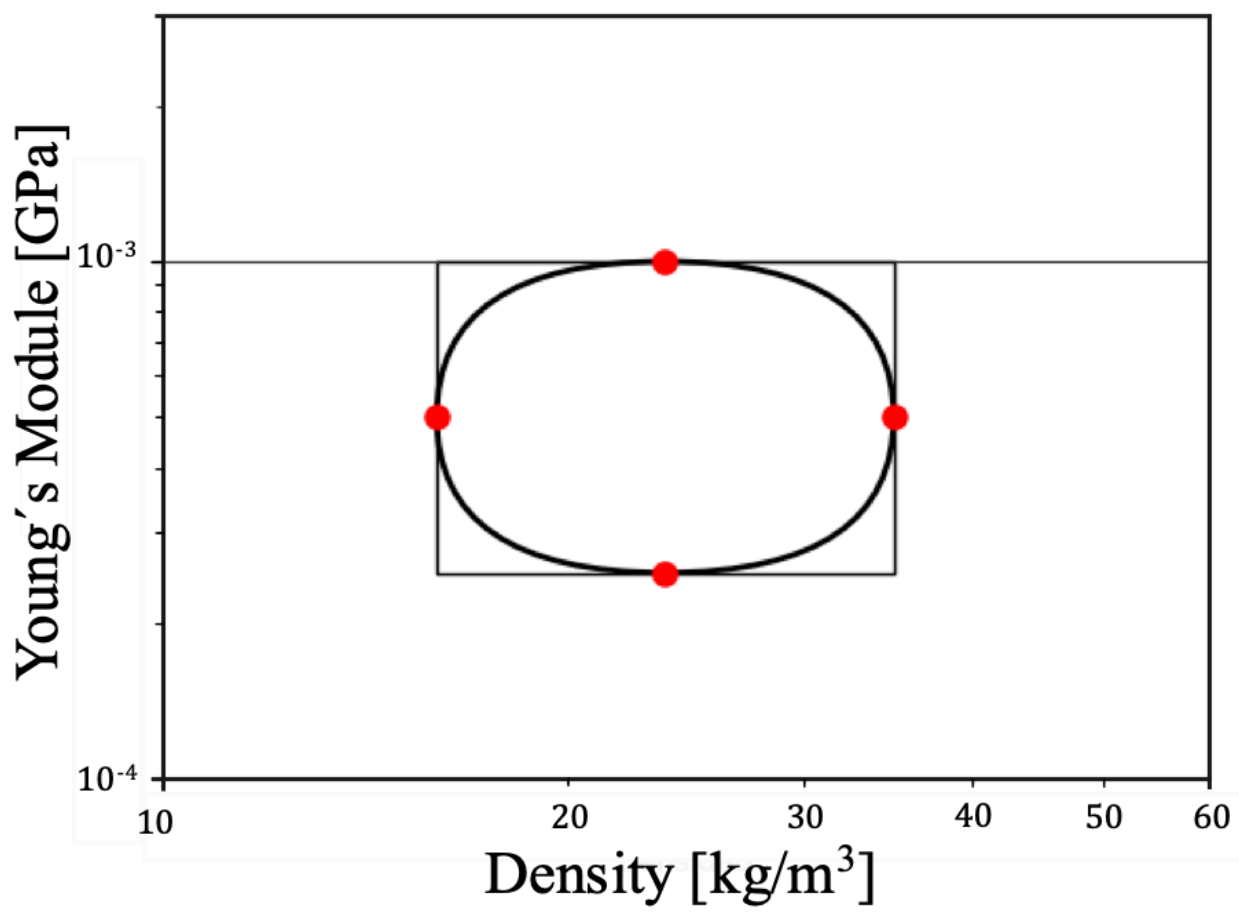

Fig. 2. Ellipse diagram

ii) Region diagrams. -The $<<$ Graph regions $>>$ function was applied to sketch the regions diagrams. As shown in the Figure 3., this function identifies all vertex of each rectangles that were created with the previous process and then, with the help of the $<<$ ConvexHull $>>$ Python function, the external points that will serve as guides for drawing the envelope are determined.

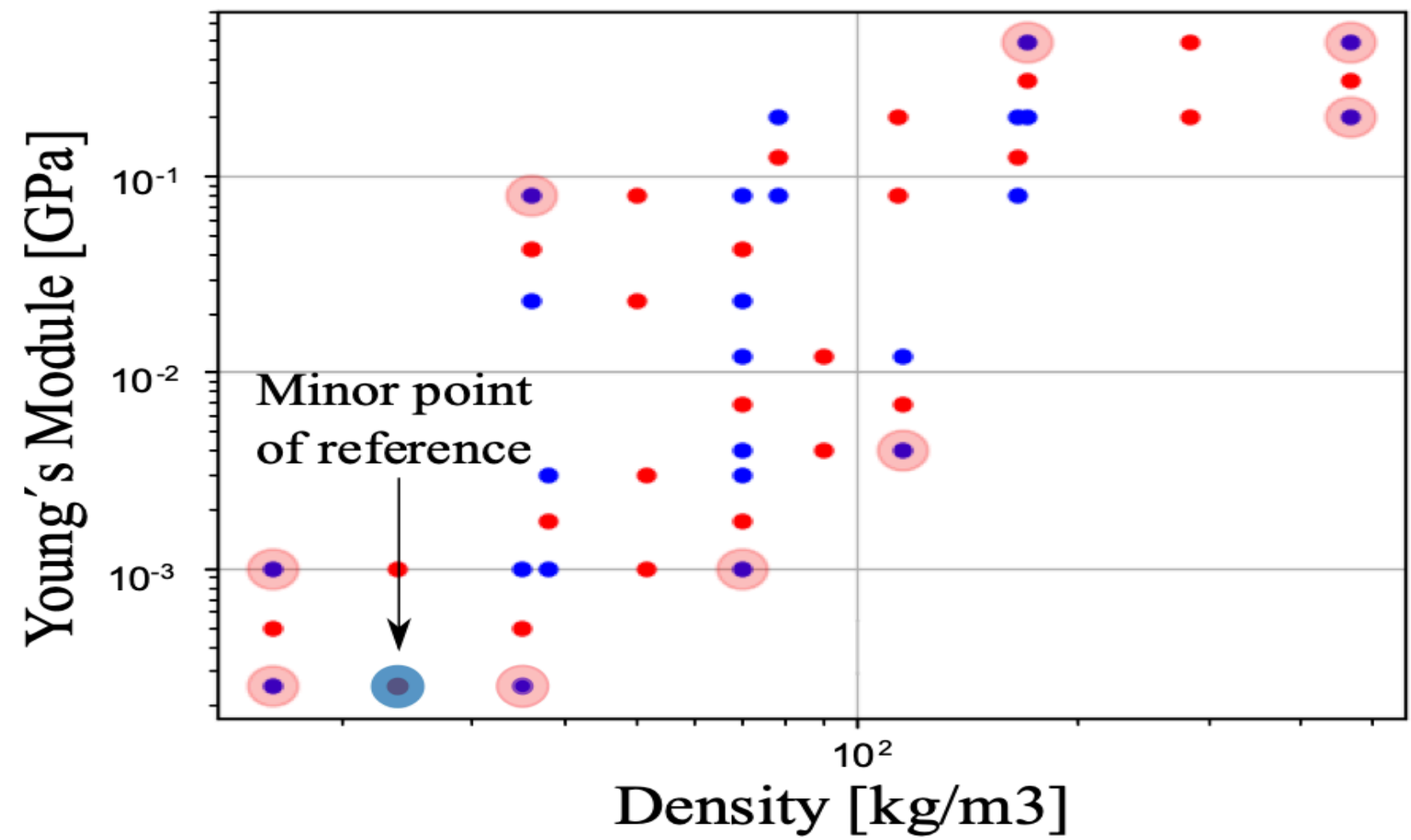

Fig. 3. External points obtained with the ConvexHull function. 
On the other hand, once the external points have been determined, the $<<$ contour $>>$ function was used with the purpose of construct an irregular polygon that are shown in the Fig. 4. Finally, the $<<$ CURVE3D $>>$ function included in the Matplotlib library is applied to generate an inscribed envelope in the irregular polygon that was created with the previous function.

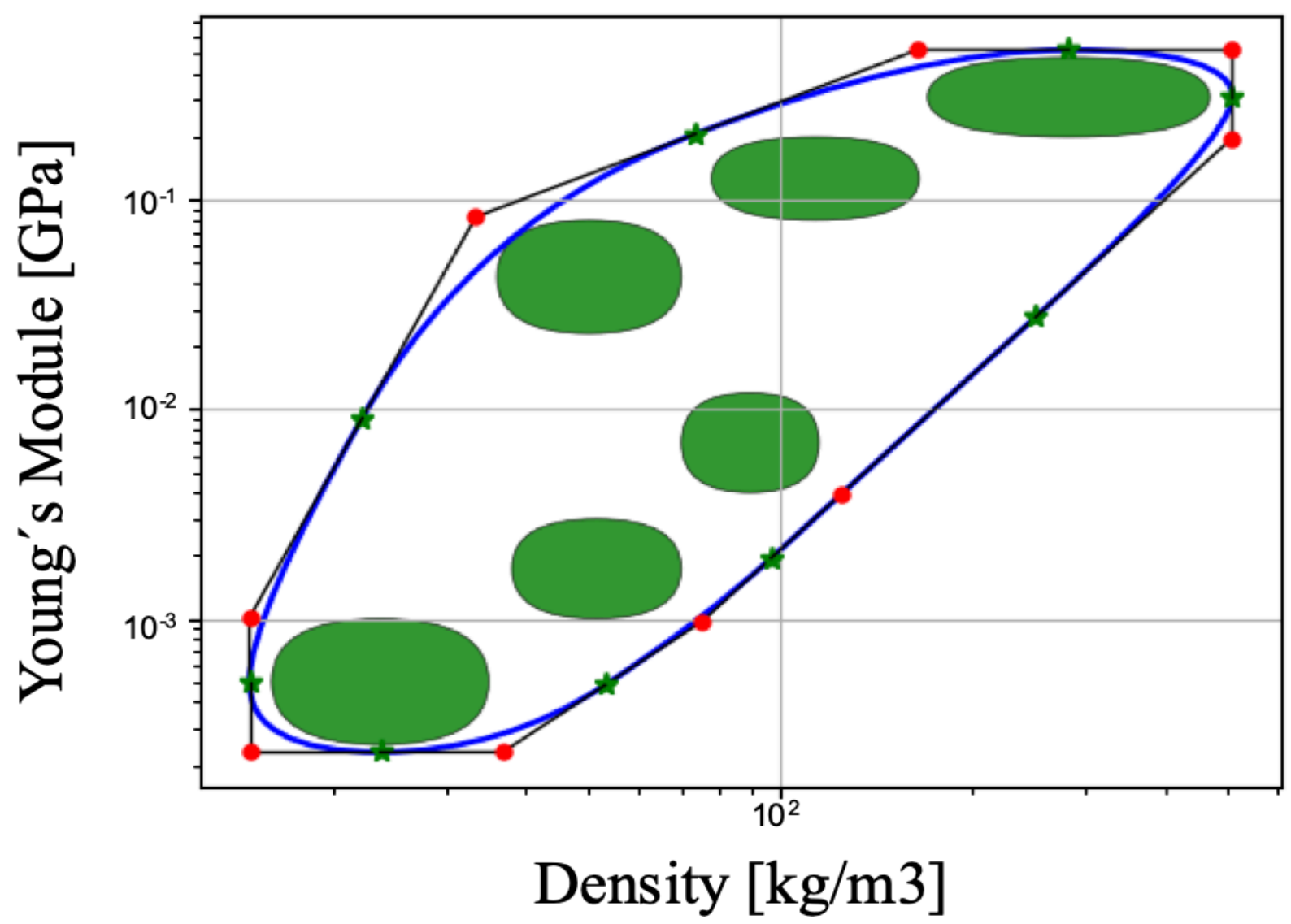

Fig. 4. Polygon obtained with the Contour function.

Graph material indices. - In addition, the presented code includes a $<<$ Graph linelndex $>>$ function, which allows graphing the material index on each Ashby Charts. This function employs as input data one point located into the diagram and slope of the line. The point is obtained by clicking on any part of the graphics area, while the slope is specified by the user according to the index obtained in the resolution of an engineering problem.

\section{Development of the graphical user interface (GUI)}

For the development of the Graphical user interface, the "wxPython" library was applied. This library contains various tools and options that allow creating quickly programs with a robust GUI. The GUI presented in this study was design according to the functions, which are described in the previous sections.

\section{Results and Discussions}

The results obtained with the programming code that have been developed in this study are shown and discussed in this section. 


\section{Results}

According to the information included in the database, the code is capable of generating three Ashby charts. The first Ashby charts is shown in the Figure 5 and relates Young's Modulus vs Density. The second Ashby charts relates the Mechanical Resistance vs Density and it is present in the Fig 6a. Finally, the third Ashby diagram is shown in the Fig. 6b. and relates two thermal properties: Thermal expansion coe? cient vs Thermal conductivity.

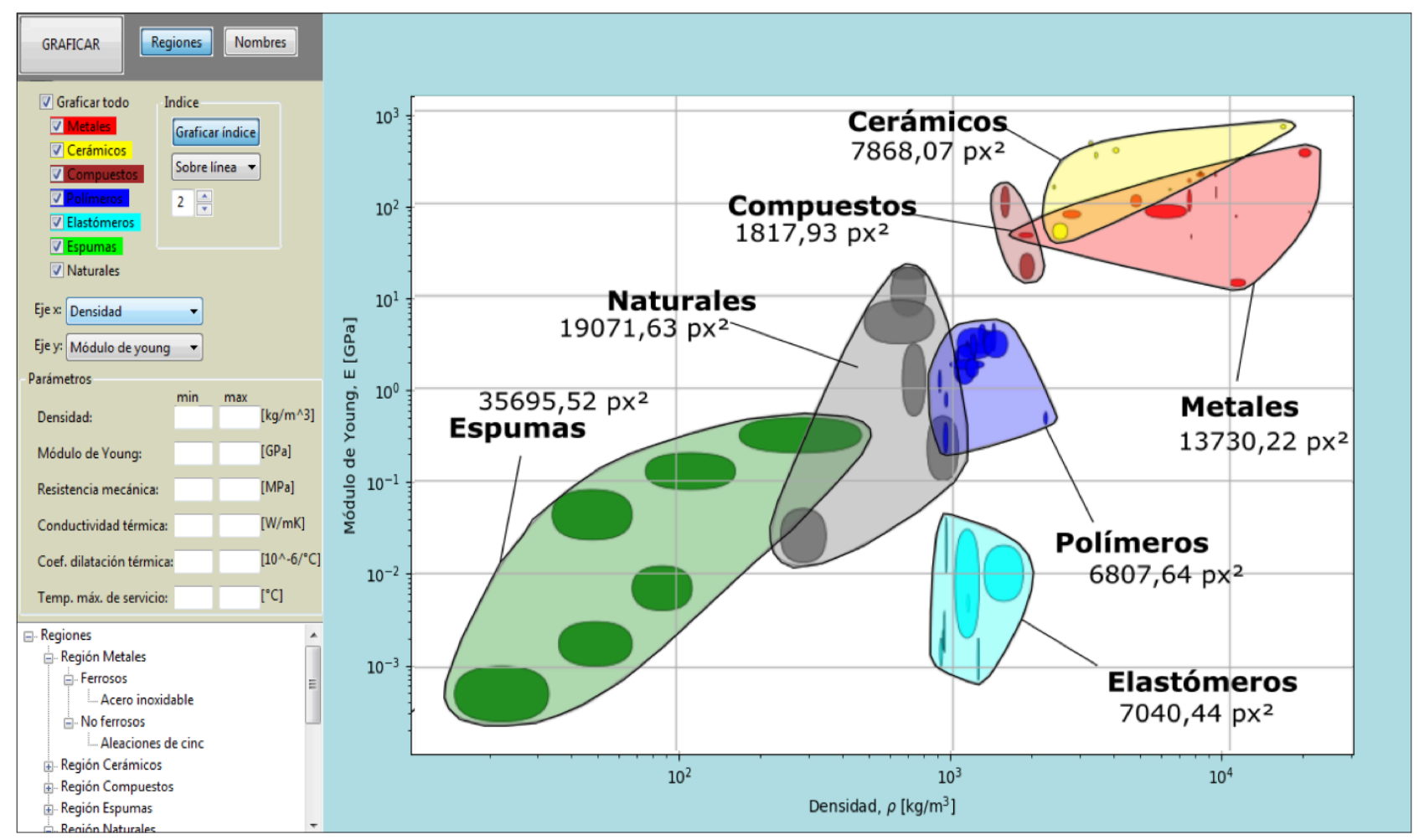

Figure 5: Graphical interface and Ashby chart of Young's modulus vs Density obtained.

In addition, the Fig. 5. shown the result of the implementation of the GUI. This interface consists of 2 panels that relate the functions implemented: a graphical panel and a control panel. Regarding the last point, the control panel is divided in the next sections: button section, material family selection section, property selection section, parameters section, material tree section and index selection section. Moreover, the graphical panel allows to display one or more material families, draw the material ranges, group them by regions, filter them according to the defined parameters and display them in the graphical panel.

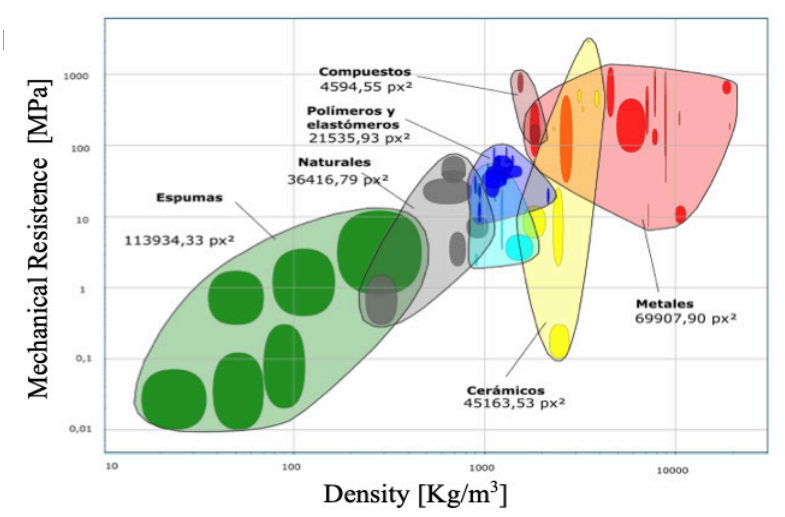

Fig. 6a. Obtained Ashby chart: Mechanical Resistance vs Density

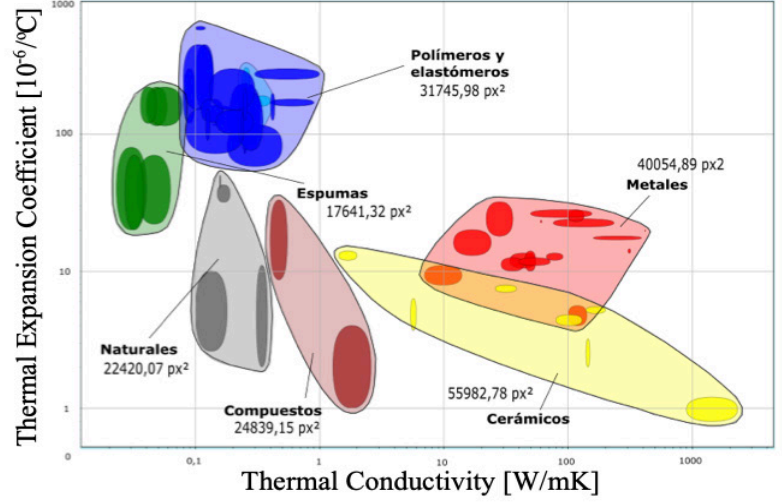

Fig. 6b. Obtained Ashby chart: Young' modulus vs Density. 
To determine whether the graphs obtained are suitable for the selection of materials, we proceed to compare these diagrams with the diagrams presented in the CES Edupack 2017 software. The diagrams were analyzed individually by comparing their shape and size using free Inkscape software as shown in the Fig. 7. Based on this comparison a relative error of each diagram was determined, then a study was conducted globally by weighting each area relative to the entire diagram, thus obtaining the absolute error.

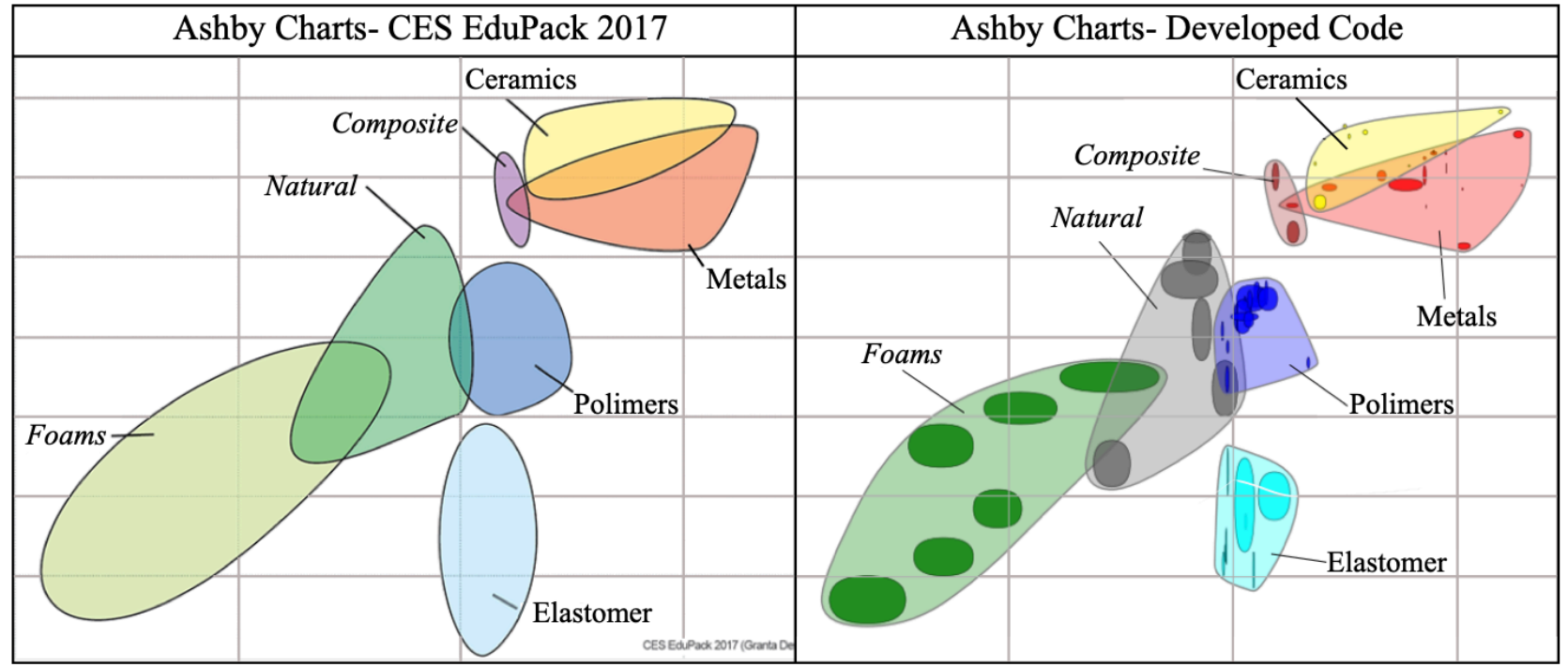

Fig. 7. Graphical interface and Ashby chart of Young's modulus vs Density obtained.

i) Analysis of Ashby Chart: Young's Modulus vs. Density

This chart is shown in the Fig. 6a. and was made using 65 materials. The envelopes of natural materials and metals have a weighted error of $0.04 \%$ and $0.96 \%$ respectively, this is because the materials of these regions are known and have been studied extensively. At the composite region, the error is $0.21 \%$ because only two material classes are used. It is noticeable that the elastomers region is the one with the highest error with $4.98 \%$ since Ashby chart considers experimental materials that have a probability of having a Young module value of less than $10 \mathrm{e}-3$. For ceramic, foam and polymer regions, the error is between $2 \%$ and $4 \%$, this error depends on variations in the value ranges of the properties.

Table 2. Comparison between CES 2017 and Developed Code for the Ashby chart: Young's Modulus vs density.

\begin{tabular}{|l|l|l|l|l|}
\hline Material & CES Edupack [px2] & Developed Code [px2] & Relative Error [\%] & Absolute Error [\%] \\
\hline Ceramics & 10837,95 & 7868,07 & 27,40 & 2,78 \\
\hline Metals & 14757,95 & 13730,22 & 6,96 & 0,96 \\
\hline Foams & 37958,06 & 35695,52 & 5,96 & 2,12 \\
\hline Elastomer & 12355,62 & 7040,44 & 43,02 & 4,98 \\
\hline Polymers & 10163,86 & 6807,64 & 33,02 & 3,14 \\
\hline Composite & 1591,82 & 1817,64 & 14,20 & 0,21 \\
\hline Natural & 19116,25 & 19071,63 & 0,23 & 0,04 \\
\hline Total & 106781,51 & 92031,45 & & 14,24 \\
\hline
\end{tabular}


The materials used to recreate the diagram which shown in the Fig. 6b. were 66. This diagram is the one that presents the highest error of the 3 analyzed, in general the shape of the regions is similar in both diagrams; however, an appreciable variation can be observed in the regions of polymers and elastomers.

Table 3. Comparison between CES 2017 and Developed Code for the Ashby chart: Mechanical strength vs density.

\begin{tabular}{|l|l|l|l|l|}
\hline Material & CES Edupack [px2] & Developed Code [px2] & Relative Error [\%] & $\begin{array}{l}\text { Absolute Error } \\
{[\%]}\end{array}$ \\
\hline Ceramics & 41945,73 & 45163,53 & 7,60 & 1,40 \\
\hline Metals & 78433,68 & 69907,90 & 10,87 & 2,75 \\
\hline Foams & 101689,11 & 113934,33 & 12,04 & 3,94 \\
\hline $\begin{array}{l}\text { Elastomer and Po- } \\
\text { lymers }\end{array}$ & 30697,71 & 21535,93 & 29,85 & 2,95 \\
\hline Composite & 6208,55 & 4594,55 & 26,00 & 0,52 \\
\hline Natural & 51584,85 & 36416,79 & 29,40 & 4,88 \\
\hline Total & 310559,63 & 291553,03 & & 16,08 \\
\hline
\end{tabular}

The error in this area was $2.95 \%$, the other considerable errors belong to foams and natural materials with $3.94 \%$ and $4.88 \%$ error respectively. Finally, composite and ceramics materials occupy the lowest error values with $0.52 \%$ and $1.04 \%$ respectively.

iii) Analysis of Ashby Chart: Thermal expansion vs. the thermal conductivity

For developed the diagram that shown in the figure $6 b, 63$ materials were used. When comparing the shape of the graphs it can be seen that them are in the correct position, each region is similar in both the CES and the developed code. In the Table 4. the two most significant errors are in the region of ceramics and metals, with values of $3.94 \%$ and $4.72 \%$ respectively. Despite that, the rest of the materials presents a low error reason why the code is considered valid for the recreation and presentation of the properties of the materials in bubble diagrams.

Table 4. Comparison between CES 2017 and Developed Code for the Ashby chart: Thermal expansion vs. the thermal conductivity

\begin{tabular}{|c|c|c|c|c|}
\hline Material & $\begin{array}{c}\text { CES Edupack } \\
\text { [px2] }\end{array}$ & $\begin{array}{c}\text { Developed } \\
\text { Code [px2] }\end{array}$ & $\begin{array}{c}\text { Relative Error } \\
{[\%]}\end{array}$ & $\begin{array}{c}\text { Absolute } \\
\text { Error [\%] }\end{array}$ \\
\hline Ceramics & 47935,30 & 55982,78 & 16,79 & 3,94 \\
\hline Metals & 49698,11 & 40054,89 & 19,40 & 4,72 \\
\hline Foams & 17312,41 & 17641,32 & 1,90 & 0,16 \\
\hline $\begin{array}{c}\text { Elastomer and } \\
\text { Polymers }\end{array}$ & 36458,10 & 31745,98 & 12,92 & 2,31 \\
\hline Composite & 27381,87 & 24839,15 & 9,29 & 1,24 \\
\hline Natural & 25540,12 & 22420,07 & 12,22 & 1,53 \\
\hline Total & 204325,91 & 192684,19 & & 13,90 \\
\hline
\end{tabular}




\section{Conclusions}

In the present study a Python code was proposed to generate a scatter diagrams which are knows as Ashby charts. Obtained results shown that the Ashby charts obtained with the proposed code are suitable for use in the selection of materials using the graphical method, due to their great similarity to the original Ashby diagrams, generally obtaining errors of less than $15 \%$. The shape and size of the envelope of the regions depends on the existing materials in the database and the ranges of their properties, so it generates discrepancies with the envelopes of the Ashby diagrams, but their error is low as shown in section 3.

Acknowledgments. The authors gratefully acknowledge the support provided by Computer Laboratory of Escuela Politécnica Nacional for the development of this study, which is part of the research project PIJ 17-13.

\section{References}

1. H. A. González and D. H. Mesa, "La importancia del método en la selección de materiales", Scientia et Technica, vol. 1, pp. 175-180, May 2004.

2. M. F. Ashby, Materials Selection in Mechanical Design. 3rd Ed. Oxford: Elsevier, 2005.

3. R. Chrobak and M. L. Benegas, "Herramientas computacionales y el aprendizaje significativo" in Technology Proc. of the First Int. Conference on Concept Mapping, Pamplona, Spain, 2004.

4. G. K. Vijayaraghavan and S. vishnupriyan, Design of Machine Elements. 4th ED. R. G. Budynas and J. K Nisbett, Shigley's Mechanical Engineering Design. 9th ED. New York: Mc-Graw Hill, 2008.

5. E. Flores-Johnson, J. Carrillo, C. Zhai, R. Gamboa, Y. Gan and L. Shen, "Microstructure and mechanical properties of hard Acrocomia mexicana fruit shell", Scientific Reports, vol. 8, no. 1, 2018.

6. E. Bird, A. Bowden, M. Seeley and D. Fullwood, "Materials selection of flexible open-cell foams in energy absorption applications", Materials \& Design, vol. 137, pp. 414-421, 2018.

7. M. Porter and P. Niksiar, "Multidimensional mechanics: Performance mapping of natural biological systems using permutated radar charts", PLOS ONE, vol. 13, no. 9, p. e0204309.

8. A. Silva, "Desarrollo del código de programación para procesamiento de imágenes aplicada en fundiciones nodulares", bachelor thesis, Escuela Politécnica Nacional, Quito, Ecuador, 2017.

9. W. D. Callister, Fundamentals of Materials Science and Engineering. 4th ED. Salt Lake City: Wiley, 2011.

10. N. P. Cheremisinoff, Materials selection deskbook. 1st ED. New Jersey: Noyes, 1996. 